\section{IJ\$ER}

ISSN: 2149-5939
International Journal of Social Sciences and Education Research

Online, http://dergipark.gov.tr/ijsser

Volume: 3(2), 2017

\title{
Çevresel istihdam bağlamında yeşil işlerde eğitim ve beceri kazandırma*
}

\section{Training and gaining skills at green jobs in the context to environmental employment}

\author{
Yeliz Yeşil ${ }^{1}$ Fatma Fidan²
}

\begin{abstract}
$\ddot{O} z$
Received Date: $01 / 09$ / 2016

Accepted Date: 03 / 02 / 2017

Yeşil ekonominin değişen insan kaynă̆ taleplerini karşılayabilmesi açısından sürekli ĕ̆itim, gelişme ve uyum becerisi gereklidir. Yeşil ekonomiye geçişle yeşil işler önem kazanmıştır. Yeşil işlerin araştırılması gelecekte iş piyasasının ihtiyaç duyacağı işlere ilişkin işgücünün yetiştirilmesi ve bu işlere yönelik işgücünün yetiştirileceği eğitim birimlerinin kurulmasına yönelik çalışmaların yapılması açısından gereklidir. Bu çalışmada yeşil işlerin gelişimi, özellikleri ve mevcut mesleklerden farklılıkları incelenerek, yeşil işlere yönelik eğitim ve beceri kazandırma faaliyetlerinin değerlendirilmesi amaçlanmışıtır. Yapılan çalışmada, yeşil işlerin karakteristik özelliklerinin farklı bir eğitim ve beceri kazandırma sürecini gerektirdiği görülmektedir. Eğitim süreci şu özeliklere sahip olacaktır;

- Dinamik, sürekli değişim ve gelişim göstermekte,

- Çoklu beceri ve bilgi sunmakta,

- Interaktif bir süreç oluşmakta,

- Fakl kurum ve birimlerin işbirliğini gerekli kılmakta,

- Disiplinler arasi olmaktadir.

Yeşil işler farklı eğitim programlarını ve süreçlerini gerektirmektedir. Yeşil işlerin genellikle "yerel” nitelik göstermesi buna uygun eğitim süreçlerine ihtiyaç duymaktadır. Yeşil işler ve işgücü piyasası bakımından etkin politikalar geliş̧tirilmelidir. Bu kapsamda yeşil faaliyet alanları ile ilgili eğitim modülleri belirlenmeli, sürdürülebilirlik çerçevesinde sistemler kurulmalıdır.
\end{abstract}

Anahtar sözcükler: Yeşil işler, yeşil yakalıların eğitimi, çevresel istihdam.

\section{Abstract}

Continuous training, development and adaptation skills are necessary for the green economy to meet the changing human resource demands. Green jobs have gained importance in the transition to green economy. Researching green jobs are necessary for helping staff development at labor market and building training units which train human resources for these jobs. The aims of this study are examining the development of green jobs and their characteristics and differences from existing professions and evaluating training and gaining skills activities about green jobs. In this study, it appears that requires a different educational and training process of the characteristics of green jobs. The educational process will have the following characteristics;

- Dynamic, shows continuous change and development,

- It offers multiple skills and knowledge,

- It consists of an interactive process,

- It requires the cooperation of different institutions and bodies,

- It is interdisciplinary.

Green jobs require different training programs and processes. Green jobs are often "local" in nature and need appropriate training processes. Effective policies should be developed for green jobs and the labor market. Within this scope, training modules related to green activity areas should be determined and systems should be established within the framework of sustainability.

Keywords: Green jobs, green collars training, environmental employment.

*Bu çalışmanın özeti "The Book of ICSSER Abstracts 2nd International Conference on Social Sciences \& Education Research November 4-6, 2016 İstanbul-TURKEY" bildiri kitabında yer almaktadır.

${ }^{1}$ Yrd.Doç.Dr.,Bilecik Şeyh Edebali Üniversitesi,Söğüt MYO,Bilecik, yeliz.yesil@bilecik.edu.tr.

${ }^{2}$ Doç.Dr.,Sakarya Üniversitesi,Sakarya, ffidan@sakarya.edu.tr. 
Yeşil, Y., Fidan, F. (2017). Çevresel istihdam bağlamında yeşil işlerde eğitim ve beceri kazandırma. Interna-

tional Journal of Social Sciences and Education Research, 3(2), 607-618.

\section{Giriş}

Günümüz ekonomik sisteminde gelişme ve istihdam politikaları, sürdürülebilirlik ve kurumsal sosyal sorumluluk bağlamında çevrenin korunması ve yenilenebilir enerji kaynaklarının kullanımı gibi temel anlayışlar çerçevesinde yeniden tanımlanmaktadır. Yani anlayış ve değerlerin toplumlar ve örgütler üzerinde önemli değişimlere yol açması beklenmektedir. Özellikle örgütlerde insan kaynaklarının biçimini değiştirici özelliği ile dikkat çekmektedir (http://www.kigem.com/insan-kaynaklarinda-yesil-yakalilar-donemi.html). Yeşil ekonominin ortaya çıkardığ 1 "yeşil işler" yapısı ve özelikleri itibariyle geleceğin istihdam alanı olarak görülmektedir.

Yeşil işlerin kapsamı, sınıflandırılması ve istihdam üzerindeki etkileri ile ilgili olarak farklı yaklaşımlar bulunmaktadır. Genel olarak yeşil işler; çevreyi, doğayı, eko-sistemi ve biyolojik çeşitliliği korumaya yönelik düzenlemeleri içeren, enerji ve doğal kaynakların kullanımında verimliliği ön plana çıkaran, sera gazı emisyonunu düşürmeyi, atık ve kirlilik üretimini düşük tutmayı hedefleyen işler olarak ele alınmaktadır. Düşük karbonlu ve sürdürülebilir ekonomilerde çevreyi korumayı ve iyileştirmeyi hedefleyen ve eko-sistemi oluşabilecek zararlardan korunmayı sağlayan güneş panellerinin kurulumu, bio-yakıt ve hibrid araç üretimi, organik tarım, yalıtım, rüzgâr tribünleri kurulumu gibi işler yeşil işler olarak adlandırılmaktadır (Özsoy, 2011,s. 19).

Yeşil işlerin en önemli özelliklerinden biri de sadece çevreci olmakla kalmaması, aynı zamanda düzgün işler olmasıdır. Yeşil işlerin istihdam etkisinin pozitif, negatif ya da nötr olacağını savunan görüşler bulunmaktadır. Brüt ve net istihdam etkileri de ele alınan diğer konular arasındadır. Bu çalışmada farklı yaklaşımlara göre yeşil işler ortaya konmakta ve yeşil işlerin istihdama olası etkileri tartışılmaktadır.

\section{Yeşil işler ve yeşil yakalılar}

İklim değişimi, küresel ısınma, doğal kaynakların tükenmesi ve biyolojik ve doğal ortama zarar veren atıkların artması, "hızlı büyüme" anlayışı yerine "sürdürülebilir büyüme" anlayışını içeren "yeşil ekonomiyi" ön plana çıkarmıştır. Ülkelerin gelişme ve istihdam stratejilerini de bu anlayış çerçevesinde geliştirme çabasına girdikleri görülmektedir. Yeşil işler-yeşil istihdam, hem dünyada hem de ülkemizde doğal kaynakların korunması ve farklı refah rejimlerinin uygulanabilirliği açısından yeni bir kavramdır. BM Çevre Programına göre yeşil ekonomi, toplumda refahın ve sosyal adaletin artması yanında, çevreyi tehdit eden riskleri azaltabilen ekonomik yaklaşım olarak ele alınmaktadır. Bu yeni yaklaşım, ekonomik büyümeyi sürdürmenin yanında, sosyal refahın adil dağılımını sağlamak gibi toplumsal yararları yanında çevresel riskleri ve ekolojik zararları önlemeyi de hedeflemektedir. Yeşil ekonomi, çevresel tahribat, biyolojik zenginliğin yok olması ve doğal kaynakların kullanımındaki israfı ortadan kaldırırken ekonomik büyüme ve kalkınmayı da başarılı bir biçimde gerçekleştirmesiyle de giderek daha fazla kabul görmektedir. Bu bağlamda ülkeler, yeşil ekonomiye geçişle ilgili yapısal değişimleri yönetirken aynı zamanda yeşil endüstriler, iş ve teknoloji geliştirme imkanlarını kullanarak, çevresel duyarlılığa sahip büyüme kaynaklarını yönlendirmeyi amaçlamaktadır. Yeşil ekonomi politikalarının ekonomik ve sektör açısından arz ve talebi uyumlu kılacak entegre stratejiler ile bütünleştirilmesi gerekir. Bu yaklaşım, yeşil ekonominin sadece krizlere karşı kısa dönemli bir araç değil, ayrıca üretim süreci ve tüketici davranışlarının dönüştürülmesi dinamiğini de ele alınmasını sağlayacaktır (http://www.oecd.org).

Yeşil ekonominin, ekonomide ve doğal çevrede sürdürülebilirlik yoluyla 8 önemli sektörde istihdamı arttırıcı etkisi de önem kazanmaktadır. Çevresel sürdürülebilirlikle yakından ilişkili 
Yeşil, Y., Fidan, F. (2017). Training and gaining skills at green jobs in the context to environmental employment. International Journal of Social Sciences and Education Research, 3(2), 607-618.

olan bu sektörler tarım, ormancılık, balıkçılık, yenilenebilir enerji, kaynak yoğun üretim, geri dönüşüm, inşaat ve taşımacılık olarak sıralanmış, gelecek 20 yılda küresel olarak 15-60 milyon ek iş firsatı sunacağı projeksiyonuna yer verilmiştir (Reyhan ve Duygu, 2015,s. 21).

Yeşil işler, işgücüne verimli çalışma ortamları sunan, yeterli gelir olanağı ve sosyal koruma sağlayan, işçi haklarına saygılı ve hayatlarını etkileyen kararlara katılım olanağı veren işlerdir. (ILO, 2013: 23). ILO'ya göre yeşil işler, ekonomilerin, girişimlerin, işletmelerin ve işgücü piyasalarının insana yakışır iş standartları sağlayan, sürdürülebilir ve düşük karbon ekonomisine geçişi ile gerçekleşebilecek niteliktedir. ILO yirmi birinci yüzyıl için iki temel problem ile mücadele ettiğini belirtmektedir. Bunlardan ilki; zararlı iklim değişikliğinin şimdiki ve gelecek nesillerin hayat kalitesini ciddi şekilde tehlikeye atacağı gerçeği ve doğal kaynakların bozulması; ikincisi de, yoksulluk ve işsizliktir (Başol,2013:1).

Yeşil ekonomi ve yeşil büyümede gerçekleştirilen ilerlemenin ölçülmesinde, çevre ve doğal kaynakların kullanımı ve korunması gibi maddi refahı ele alan unsurlar yanında genel anlamda yaşam kalitesi ile ilgili farklı göstergeler ve veriler söz konusudur. Bu noktada "yeşil işler" yeşil ekonomin sadece sonucu değil, yeşil ekonomin gerçekleştirildiğinin de bir göstergesi olarak ele alınmalıdır. Son dönemde ortalama 2.3 milyon işgücünün yeşil işlerde istihdam edildiği yönünde veriler mevcuttur. Yeşil iş yaratma sürecinin yakın gelecekte hem gelişmiş ülkelerde hem de bazı gelişmekte olan ülkelerde giderek artması beklenmektedir (Özsoy, 2011,s.19).

Energy Revolution 2012 Raporu'na göre rüzgar enerjisi 2030 yılına kadar 1,7 milyon insanın istihdam edilmesini sağlayacak ve 2020 yılına kadar 520.000' den fazla işgücü de rüzgar enerjisi kullanımında istihdam edilecektir. 2030 yılından sonra da off-shore rüzgar santrallerinde yüzde 62 oranında artış ile toplam 794.079 istihdam sağlanacağ 1 ifade edilmiştir. Euractiv' in haberinde de; günümüzde dünya genelinde 4 milyon işgücüne istihdam sağlayan temiz teknoloji sektörünün 2020 yılında 20 milyon işgücüne istihdam sağlayacağı öngörülmektedir (Binici,2013).

ILO yeşil işleri sürdürülebilir büyümenin odağında yer alan ve doğal çevrenin korunması ile beraber ekonomik büyüme ile toplumsal katılımı içeren, hükümetler, çalışanlar ve işverenlerin de değişimin aktif aktörleri olarak yer aldığı olgu biçiminde tanımlamaktadır. ILO, tüm işletme ve iş piyasasında yeşil süreçlerini desteklediğini sıklıkla vurgulamaktadır (Reyhan ve Duygu, 2016).

Hangi işlerin yeşil işler kapsamında olduğuna dair fikir birliği olmasa da, yeşil işlerle ilgili meslekler aşağıdaki gibi sıralanabilmektedir (Çatalkaya, 2009):

- Yenilenebilir Enerji Uzmanı (Güneş, Rüzgar, Su, jeotermal enerji Uzmanı)

- Yenilenebilir Enerji Mühendisi

- Rüzgar Enerjisi Uzmanı

- Yeşil Pazarlama (Green Marketing) Danışmanı

- (Yeşil İ.K.)Yeşil İnsan Kaynakları Yönetmeni

- Yenilenebilir Enerji Hukuku (Çevre ve Enerji Hukuku) Uzmanı/Danışmanı

- Organik Tarım Mühendisi

- $\quad$ Yeşil ( Ekolojik) Turizm / Tatil Uzmanı 
Yeşil, Y., Fidan, F. (2017). Çevresel istihdam bağlamında yeşil işlerde eğitim ve beceri kazandırma. International Journal of Social Sciences and Education Research, 3(2), 607-618.

\section{Yeşil işlerin Türkiye'de genel durumu}

Ekonomilerin düşük karbonlu ve sürdürülebilir anlayışa geçişi, farkl1 ve yeni sektörlerin oluşumuyla çok sayıda yeşil iş ortaya çıkabilir ve ekonomik büyüme açısından lokomotif olabilir. Türkiye'de yeşil iş potansiyelinin yüksek olduğu, yeşil iş yaratma kapasitesi fazla olan sektörlerin yaygınlığı avantajlı bir durumu ortaya koymaktadır. Ancak, yeşil işlere yönelik kapasitenin kullanılabilmesi ve beklendiği gibi yeni istihdam imkanları sunabilmesi ve yaratabilmesi, çevresel sürdürülebilirlik konusunda farkındalığın arttırılması, hukuki düzenlemenin yapılması ve stratejik sektörlerin belirlenerek özel sektörün bu alanlardaki rolünün güçlenmesi ile sağlanabilecektir. $\mathrm{Bu}$ anlamda işletmelerin yeşil iş istihdam yaratımında, sosyal ve çevresel yatırımların güçlendirilmesinde önemli aktör oldukları tartışmasız kabul görmektedir. Bu çerçevede önderlik rolüne sahip işletmelerin kaynak kullanımının azaltılması ve iklim değişikliği ile mücadelede de değerli işlevleri olacağı genel kabul görmektedir (http://www.ilo.org).

TÜIK' in çevresel harcamalar çerçevesinde ele aldığı temel iş grupları; atık yönetimi, su hizmetleri, atık su yönetimi hizmetleri ve diğer konular olarak sıralanmaktadır. 7 Ocak 2015'te yayınlanan ve 2013 yılı verilerine göre, 2013 yılında toplam çevresel harcamaların yüzde 77,4'ü kamu sektörü tarafından, yüzde 22,6'sı ise özel sektör tarafından gerçekleştirilmiş ve kamuda en büyük payı yüzde 80 ile belediyeler almıştır. TÜİK bu veriler çerçevesinde kamu kuruluşları, il özel idareleri, girişimler ve organize sanayi bölgelerinde çevresel faaliyet kapsamında istihdam edilen kişi sayısını yine 2013 yılı için 65 bin 124 olarak açıklamıştır. Cinsiyet dağılımında da kadınların sadece yüzde 10'luk bir orana sahip olduğu görülmektedir. Bunda değerlendirme kapsamına alınan işlerin çoğunlukla mavi yakalı denebilecek ve kol gücü gerektiren işler olmasının da etkileri olduğu vurgulanmaktadır (Çelik,2016).

Yenilenebilir enerji üretimi iş yaratma açısından önemli potansiyeli sahiptir. "The World Wind Energy Association, rüzgar enerjisinde 2.1 milyon, güneş enerjisinde 6.3 milyon ve bio yakıt alanında 12 milyon olmak üzere toplam 20 milyonun üzerinde ek istihdam imkanının var olacağını ifade etmektedir. Türkiye'de ise, 2020 yılına kadar 400- 450 rüzgar santrali kurulması ve yaklaşık 5 bin 500-6 bin işgücü açısından iş imkanının sunulması öngörülmektedir. Santrallerin inşasında da 6 bin 500 işgücü için geçici işlerin yaratılması ile rüzgar enerjisi için 12 bin işgücünü istihdam edecek iş potansiyeli ortaya çıkmaktadır. Diğer yandan The European Wind Energy Association (EWEA)'nın yayınladığ 1 "Wind Directions" dergisinin 2013 Eylül özel sayısında, bürokratik engellerin aşılması ve lisanssız elektrik üretim sürecinin gelişimini sürdürmesi ile Türkiye'de yenilenebilir enerjisi sektörünün büyümeye devam edeceği ve bunun da istihdama olumlu yönde etki edeceği belirtilmektedir (Binici,2013).

Türkiye'de 5346 Sayılı Yenilenebilir Enerji Kanununun, (YEK) 2005 y1lında yürürlüğe girmesiyle yenilenebilir enerji alanında gelişmeler hızlansa da, düşük sabit fiyat garantisi gibi nedenlerle 2005 ile 2010 döneminde yenilenebilir enerji kaynaklarına yapılan yatırım sınırlı kalmıştır. Aralık 2010'da Yenilenebilir Enerji Kanununda değişiklik yapılmış ve daha yüksek sabit fiyat garantisi ve çeşitli parasal ve parasal olmayan teşviklerin getirilmesiyle 2005-2010 dönemine göre yenilenebilir enerji sektöründe canlanma görülmüştür.

Son yıllarda gerçekleştirilen yenilenebilir enerji yatırımları yanında AB ile gerçekleştirilen çevre müzakereleri Türkiye' de yeşil yakalı işlerde artışın yaşanmasını teşvik etmiştir. Kamu sektöründe çevresel süreçlerde istihdam edilenler ve özel sektörde 50. 000 işi içeren istihdamın olduğu varsayılmaktadır. Özelikle rüzgar enerjisi, çevre mühendisleri bu iş süreçlerindeki temel 
Yeşil, Y., Fidan, F. (2017). Training and gaining skills at green jobs in the context to environmental employment. International Journal of Social Sciences and Education Research, 3(2), 607-618.

alanlar olarak belirginleşmektedir. Gelecekte ise hidroelektrik santrali, rüzgâr santralleri ve jeotermal projelerin tamamlanmasıyla 100000 ' inden fazla işin yaratılacağı öngörülmektedir. Halihazırda ulaşım, inşaat, enerji, tarım gibi sektörler yeşil işlerin gelişmesi açısından potansiyelin fazla olduğu alanlar olarak ifade edilmektedir (Sungur, 2011,s. 157). Genç nüfusun ve işsizliğin fazla olması nedeniyle Türkiye'de yeşil işlerin gelişmesiyle sağlanacak yeni ve kaliteli istihdam alanları büyük önem taşımaktadır. ILO tarafından gerçekleştirilen "Yeşil Ekonomide İnsana Yakışır İşler" Projesi (Türkiye, Meksika ve Çin 2013 - 2014), yoksulluğu önleme ve toplumsal içerme sürecinde ulusal yeşil ekonomi girişimlerini güçlendirerek kadınlar ve erkekler için yeşil işler sağlama hedefine yönelmiştir. Bu bağlamda öngörülen hedeflere ulaşmak için uluslararası alandaki araştırma ve bilgi paylaşım faaliyetleri eğitim ve araştırma girişimleriyle desteklenerek, ülke düzeyindeki politika geliştirme çalışmaları gerçekleştirilmektedir (http://www.ilo.org).

Türkiye'de yeşil işlerin yoğunlaştığı sektörler ve yeşil ekonomi bağlamında sürdürülen politikalar çerçevesinde yaratılacak işlerin hangi özelliklere sahip olduğu ve hangi nitelikte işgücünü gerektirdiğine dair verilerin sunulması gerekmektedir. Bu çerçevede "Başlangıç ve ilk Görev Gücü” toplantısı 25 Nisan 2013'te Ankara'da yapılmış ve Türkiye ILO Türkiye Ofisi tarafından ILO Yeşil İşler Programı ile bir yıl boyunca gerçekleştirilecek proje ile (Efendioğlu, 2013,s. 11);

• Türkiye’ye özgü “Yeşil İşler Değerlendirme Çalışmasının” gerçekleştirilmesi,

- İlgili kamu kurumları ve sosyal aktörlerin temsilcilerinden oluşacak çok paydaşlı bir "Görev Gücü”nün kurulması ve “Görev Gücü”ne yönelik yeşil işler konusunda teknik desteklerin sağlanmasinı,

• “Görev Gücü” tarafından Türkiye için yeşil işler strateji önerilerinin geliştirilmesini öngörmektedir.

\section{Yeșil işler ve eğitim}

Geleceğin işleri olarak ifade edilen "yeşil işlerde" çalışabilmek için iyi eğitimli ve beceri kazandırılmış işgücüne hazırlıklı olunması Türkiye'nin işsizlik sorununa da çözüm getirebilecektir (Özsoy, 2011,s.19). Yeşil işlerin sayısının artması ve bu işlerde istihdamın sağlanabilmesi için farklı eğitim programları gerçekleştirilmektedir. ILO yeşil işler ile ilgili farkındalığı ve bilgi kapasitesini arttırmak için başta ILO' nun Uluslararası Eğitim Merkezi olan Turin'de olmak üzere dünyanın çeşitli bölgelerinde aktif ve sürekli eğitimler düzenlemektedir. ILO, yalnızca ekonomi bağlantılı sosyal olaylarla ilgili önemli bir aktör olmayı değil aynı zamanda yeşil işler, sürdürülebilir olma ve iklim değişikliğinin sosyal boyutlarıyla ilgilenen uluslararası aktör olmayı da hedeflemektedir. Bu nedenle ILO yeşil işler programı kapsamında altı önceliğe yoğunlaşmaktadır. Bunlar şunlardır (Başol,2013: 3) :

- İş ve iş piyasası boyutlarının analizi,

- Yeşil girişimlere uygulanabilir yaklaşımlar,

- Atık yönetiminde ve geri dönüşümde yeşil işler,

- Yenilenebilir enerji ve enerji etkinliği,

- Yeşil ekonomiye ve sürdürülebilir topluma adil bir geçiş,

- İ́klim değişikliğine uyum sağlamadır. 
Yeşil, Y., Fidan, F. (2017). Çevresel istihdam bağlamında yeşil işlerde eğitim ve beceri kazandırma. International Journal of Social Sciences and Education Research, 3(2), 607-618.

Yeşil işler programı sadece öncelikler belirleme konusunda değil aynı zamanda ülkelere önemli politik yardımlar sağlama konusunda da kayda değer adımlar atmaktadır. Bu adımlar şunlardır (Başol,2013: 4):

- İklim değişikliği ve sürdürülebilir gelişme (UNFCCC, Rio+20) üzerine tartışan uluslararası politikalar yaratma,

- Yeşil işler potansiyelinin küresel analizi ve ülke değerlendirmesi,

- Farkındalığın artması, ulusal politika çalıştayı ve politika uygulamaları konusunda doğrudan teknik yardım;

- $\quad$ Küresel ve bölgesel eğitim kurslarıdır.

$\mathrm{Bu}$ hususlar yeşil ekonominin gelişmesini destekleyecek ve istihdam artışı sağlanabilecektir. Belirtildiği üzere küresel ve bölgesel kursların artışının sağlanmasıyla da yeşil ekonominin ihtiyaç duyduğu kalifiye eleman karşılanacaktır.

Türkiye'de de ilk defa 2012- 2013 yılında ve 2014-2015 öğretim y1lı itibari ile Türkiye'de 30 mesleki ve teknik okulda Yenilenebilir Enerji Teknolojileri adı altında bir alan bulunmaktadır. Bu okullardan 27 sinde bu alanın Güneş Enerjisi Sistemleri dalı, 17 sinde rüzgar teknolojileri dalı bulunmaktadır. Mesleki ve teknik liselerin bu alanları rüzgar ya da güneş enerji santrallerinde, rüzgar ve güneş tribünü kurulum firmalarında, güneş ve rüzgar tribünü üreten firmalarda, güneş paneli üreten firmalar için işgücü üretmektedir. Ayrıca bu alan mezunları diğer elektrik santrali gibi yerlerde de çalışabilmektedir. Mesleki ve teknik ortaöğretim kurumlarının mezunlarının işe girmek yerine yükseköğretim kurumlarına yönelmeleri durumunda sınavla girebilecekleri bölümler ve sınavsız geçiş hakları olan 2 yıllık bölümler de mevcuttur. Mesleki ve teknik eğitim kurumlarının Yenilenebilir Enerji Teknolojileri Alanı mezunlarının sınavsız geçiş yapabileceği 2 yıllık meslek yüksek okulların bölümleri 1. Alternatif Enerji Kaynakları Teknolojisi ve 2. Elektrik Enerjisi Üretim İletim ve Dağıtımı bölümleridir ( Karakul, 2015,s. 395).

Mesleki ve teknik ortaöğretim kurumlarından mezun olan ancak mühendislik fakültelerine girişte merkezi yerleştirme sınavında dezavantajlı durumda olan öğrencilerin de mühendis olabilmeleri için 2009 yılında kurulmuş, ilk defa 2010-2011 öğretim yılında öğrenci almaya başlamıştır. Bu öğrenciler meslek liselerinden belirli bir alanın temel becerileri sahip olarak mezun olmuş ve sanayi ve büro işleri için ara eleman olarak yetiştirilmiştir. Bu potansiyel işgücünün nitelik birikiminin tekrar eğitilmek suretiyle değerlendirilmesi ve işgücü piyasasına mühendis olarak kazandırılması amacıyla kurulan Teknoloji Fakültelerinin genel lise mezunlarının bulunabileceği genelde sayıca çok az; sadece meslek lisesi mezunlarının tercihte bulunabileceği ayrı ve genelde çok fazla kontenjanları bulunmaktadır. Mesleki ve teknik ortaöğretim kurumlarının Yenilenebilir Enerji Teknolojileri alanı mezunlarının alanları ile ilişkili olarak girebildikleri Teknoloji Fakültesi Bölümü Endüstriyel Tasarım Mühendisliği bölümüdür. 4 yıllık lisans eğitimi sonrasında mezunlar mühendis unvanı almaktadır. Ancak Türkiye'de 2014-2015 öğretim yılı itibari ile sadece üç üniversitenin Teknoloji Fakültesinde Endüstriyel Tasarım Mühendisliği bulunmaktadır(Karakul,2015,s. 396).

Görüldüğü üzere son y1llarda eğitim kurumlarında yeşil ekonomiye insan gücü yetiştirilmesi açısından bölümler açılmaktadır.Lisansüstü düzeyde de yeşil ekonomiye insan gücü yetiştirmek için çeşitli bölümler vardır. Bunlar şunlardır (Karakul, 2015,s. 399): 
Yeşil, Y., Fidan, F. (2017). Training and gaining skills at green jobs in the context to environmental employment. International Journal of Social Sciences and Education Research, 3(2), 607-618.

A) Gebze Teknik Üniversitesi'nde 2002 yılında Yenilenebilir Enerji Kaynakları Araştırma Merkezi kurulmuştur. Araştırma merkezi yenilenebilir enerji kaynakları alanında doğrudan bir insan kaynağı yetiştirme programını kapsamasa da gerçekleştirilen projelerde çalışan öğretim üyeleri ve diğer kişilerin yenilenebilir enerji alanında niteliklerini arttıııı bir etkisi olmaktadır.

B) İTÜ bünyesinde 2003 yılında Enerji Enstitüsü kurulmuştur. Enstitünün 5 anabilim dalı Nükleer Araştırmalar, Yenilenebilir Enerji, Konvensiyonel Enerji, Enerji Planlaması ve Yönetimi, Enerji Bilim ve Yönetimi bölümleridir. Enstitüde enerji konusunda ileri düzey araştırmalar, projeler ve laboratuar çalışmaları yapılmaktadır. Aynı zamanda Enerji Bilim ve Teknoloji yüksek lisans ve doktora programı ile ‘ Radyasyon Bilim ve Teknoloji’ yüksek lisans programı vardır.

C)Ege Üniversitesi'nde 1978 yılında kurulmuş olan Güneş Enerjisi Enstitüsü bulunmaktadır. Enstitü şu an Enerji ve Enerji Teknolojisi adı ile iki bilim dalı içermektedir. Enstitü bünyesinde yenilenebilir enerji ve güneş enerjisi kullanımına yönelik araştırmalar ve lisansüstü tezler yürütülmektedir.

Ayrıca eğitimle ilgili örnek olarak; "Yeşil Ekonomide İnsana Yakışır İşler Projesi" kapsamında ILO Türkiye Ofisi, ILO Yeşil İşler Programı ve ILO Uluslararası Eğitim Merkezi (ITCILO) işbirliği ile 3 günlük bir ulusal çalıştay gerçekleştirilmiştir. Bilgi ve deneyim paylaşımını hedefleyen çalıştayda, ülkelerde yeşil iş stratejilerinin şekillenmesine yönelik yol haritaları ortaya konulmuştur. Çalıştay, hükümet kuruluşları ve sosyal aktörlerin delegelerini bir araya getiren çok paydaşlı Türkiye 'Proje Görev Gücü' temsilcileri için düzenlenmiştir. Çalıştayda katılımcı ve interaktif eğitimler yoluyla aşağıdaki yaklaşımlar çerçevesinde tartışmalar sürdürülmüştür (http://www.bmdergi.org/tr):

- Sürdürülebilir büyüme ve yoksulluğun önlemesi çerçevesinde yeşil ekonomi bağlamında insana yaraşır iş ve sosyal içermenin sağlanması,

- Başarılı ülke örnekleri çerçevesinde, uygulanmış projeler örnek alınarak, yeşil iş stratejileri ve uygulamaları ile ilgili deneyim paylaşımı,

- Sürdürülmekte olan proje ve uygulamaların istihdam potansiyellerinin değerlendirilmesi.

\subsection{Yeşil işlerde eğitimin özellikleri}

Eğitimin istihdamla bağının zayıflamasının önemli nedenlerinden birisi, ekonomik yapı ve süreçteki değişimlerdir ve eğitim sisteminin bu değişimlere duyarlı hale getirilerek, zayıflayan bağların güçlendirilmesi gerekmektedir. Bu duyarlılık yeni ekonomik ilişkilere göre eğitim sistemleri üzerinde uyarlanacak dönüşümlerdir. İş piyasalarındaki ve üretim biçimlerindeki değişimlerin eğitim sistemine uyarlanması noktasında politikaların üretilmesine ihtiyaç vardır. Ekonomik yapı ve üretim sürecindeki değişime bağlı olarak iş piyasası ve iş piyasasının ihtiyaç duyduğu işgücünün niteliği farklılaşmakta ve eğitim sistemini ve içeriğinde de buna paralel değişimi zorunlu kılmaktadır. Günümüzde iş piyasasında önemi giderek artan "yeşil işlere" yönelik işgücünün yetiştirilmesinde eğitim sisteminin ve sürecinin de uygun hale getirilmesi gerekmektedir. İş piyasalarında yeni bir çalışan tipi olarak yeşil yakalıların eğitim sisteminde yetiştirilmesi eğitim istihdam bağının kurulmasında önemli bir köprüdür(Karakul, 2015,s.394).

Yeşil işler bir dizi beceri, eğitim ve mesleki deneyimi gerektirmektedir. Yeşil işler özelliği gereği diğer işlere göre farklı eğitim programlarını ve süreçlerini gerektirmektedir. Yeşil işlerin genellikle "yerel" nitelik göstermesi buna uygun eğitim süreçlerine ihtiyaç duymaktadır. Doğal 
Yeşil, Y., Fidan, F. (2017). Çevresel istihdam bağlamında yeşil işlerde eğitim ve beceri kazandırma. International Journal of Social Sciences and Education Research, 3(2), 607-618.

çevrede dönüşüm ve iyileştirmeyi hedefleyen ve "yenilenebilir" olgusunu ön plana çıkaran alanları içeren yeşil işlerde istihdam edilecek işgücünün yetiştirilmesinde uygulamalı eğitimlere öncelikli olarak yer verilmelidir. Verilen teknik bilgilerin uygulamaya yönelik olarak verilmesi, teorik eğitim ile uygulama arasında güçlü bağın kurulmasına imkan vermektedir. Sürdürülebilirliğe ulaşmak, iş yapılarının ve planlarının gelecek nesillerin ihtiyaçları çerçevesinde şekillenmesi ile gerçekleşebilmektedir. Yeşil işlerde istihdam edilecek işgücüne "bilinçlendirme" faaliyeti ile başlanmalıdır. İkinci aşamada iş ile ilgili bilgi verilmeli ve uygulamalı eğitimin verileceği üçüncü aşamaya geçilmelidir. Dördündü aşamada işin gerçekleştirilmesi ve beşinci aşamada geliştirme faaliyetiyle döngü tamamlanmalıdır.

Şekil 1. Yeşil işlerde eğitim süreci

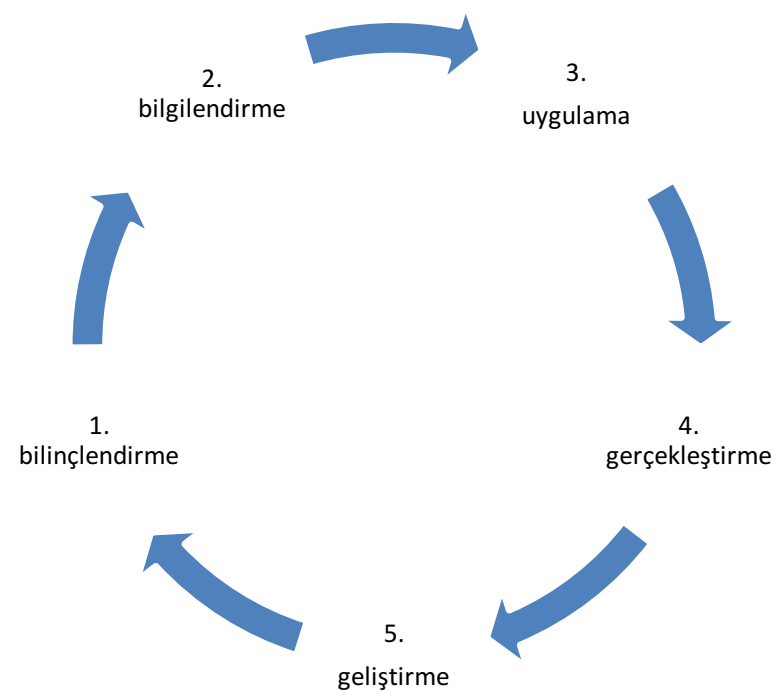

Yeşil işlerin karakteristik özelliklerinin farklı bir eğitim ve beceri kazandırma sürecini gerektirdiği görülmektedir. Eğitim süreci şu özeliklere sahip olacaktır;

- Dinamik, sürekli değişim ve gelişim göstermekte,

- Çoklu beceri ve bilgi sunmakta,

- İnteraktif bir süreç oluşmakta,

- Farklı kurum ve birimlerin işbirliğini gerekli kılmakta,

- Uygulamalı eğitimler yoluyla bilgilerin kalıcılığını ve işe aktarımını kolaylaştırmaktadır,

- Disiplinler arası olmaktadır.

Yeşil işlere yönelik eğitim süreci işin yapılması ile paralellik taşımalıdır. Eğitim belirli süreli ve kesintili bir süreç değil, süreklilik özeliği olan dinamik bir nitelik sergilemelidir. Yeşil işlere yönelik sektörlere işgücü ihtiyacını karşılayabilmek için ilgili işgücünü yetiştirecek eğitimcilerin ve eğitim kurumlarının oluşturulması gerekmektedir. Diğer yandan insan kaynakları departmanlarında çalışan uzmanların yenilenebilir enerji alanında eğitimler alması ve sektörün ihtiyaçlarına yönelik bilgi ve beceri edinmesi de çok önemlidir (Binici,2013).

\section{Sonuç ve değerlendirme}

Yeşil işlerin araştırılması gelecekte iş piyasasının ihtiyaç duyacağı işlere ilişkin işgücünün yetiştirilmesi ve bu işlere yönelik işgücünün yetiştirileceği eğitim birimlerinin kurulmasına yönelik çalışmaların yapılması açısından gereklidir. Bu çalışmada yeşil işlerin gelişimi, özellikleri ve 
Yeşil, Y., Fidan, F. (2017). Training and gaining skills at green jobs in the context to environmental employment. International Journal of Social Sciences and Education Research, 3(2), 607-618.

mevcut mesleklerden farklılıkları incelenerek, yeşil işlere yönelik eğitim ve beceri kazandırma faaliyetleri değerlendirilmesi amaçlanmıştır. Eğitim süreci çoklu bilgi ve beceri sunarak ve sürekli değişim ve gelişim göstererek bireylerin alanlarında mesleki bilgi ve becerilerinin artmasına katkı sağlamaktadır.

Yeşil işlerin ortaya çıkmasıyla beraber bu işleri yerine getirebilecek yetiştirilmiş işgücüne ihtiyaç artmaktadır. Bu sebeple bu işlerde çalışabilecek iyi eğitilmiş ve gerekli mesleki bilgi ve beceriye sahip elemanlar yetiştirilmelidir. Yeşil ekonomi istihdam artışına da katkı sağlayacaktır. Yoksullukla mücadele ve istihdam artışı sağlamak açısından da yeşil işler önem arz etmektedir. Çeşitli kuruluşların işbirliğiyle yeşil işlerin geliştirilmesi sağlanmaktadır. Ayrıca son yıllarda mesleki ve teknik liselerden, ön lisans programlarından ve dört yıllık lisans bölümlerinden yeşil ekonomiye insan gücü yetiştirilmektedir. Bu bölümler nicelik ve nitelik olarak arttırılabilir.

Sürdürülebilir ekosistem ve çevre açısından insanların yeşil işlerde istihdam edilmesi önem taşımaktadır. Bu bağlamda mevcut insan kaynağının ve gelecekteki insan kaynağı açısından eğitim süreçlerinde insanların yeşil işlere ulaşmasına imkan verecek, erişilebilirliği yüksek ve yaşam boyu öğrenme stratejilerinin desteklenmesi ve sürdürülmesi gerekmektedir. Bu bağlamda yeşil işler ve işgücü piyasası açısından aktif politikalar geliştirilmeli ve yeşil faaliyet alanları ile seçilen istihdam alanları ile ilgili eğitim süreçleri belirlenmelidir. Yeşil istihdam konusunda; işletme büyüklüklerine göre en iyi uygulamaların belirlenip farkındalığın arttırılması ve yerel yönetimlerin danışmanlık hizmeti sunması da uygulanabilecek politikalar arasındadır (Reyhan ve Duygu, 2015,s. 35). Yeşil işler ve nitelik arttırma uygulamalarının hayata geçirilmesi, iş piyasasında genç ve kadın işgücü için avantajlı istihdam politikalarını içermesi yanında yeşil bir ekonomiye geçiş Türkiye ekonomisine küresel ve yerel düzeyde önemli rekabet gücü kazandıracaktır (Efendioğlu, 2013, 11).

Özet olarak yeşil işler, geleceğin işleri olarak görülmektedir ve multi disipliner niteliğe sahip işleri sunan, yaratıcılık, hayat boyu eğitim-değişim-gelişim gerektiren dinamik işler olacaktır. Bu bağlamda yaygınlık kazanacak olan çevresel istihdamın önemli bileşenlerinden birisi, işgücünün eğitim, bilgi, beceri ve yeteneklerinin verimli ve sürdürülebilir çevre ve üretim bileşimini sağlayacak nitelikte ve bu bileşimin ihtiyaç duyduğu teknolojiyi kullanabilme yanında çok yönlü hedefleri uyumlaştırabilmeye yönelik geliştirilmesi gerekmektedir. Bu dönüşüm sürecinde eğitim ve beceri geliştirme faaliyetleri önemli bir role sahip olacaktır.

\section{Kaynakça}

Başol, O. (2013). Yeşil İşler Sürdürülebilir Girişimlerde Insan Onuruna Yakışır Işsler ve Düşük Karbon Ekonomisi, KESAM Kırklareli Üniversitesi Ekonomik ve Sosyal Araştırmalar Merkezi, Yeşil İşler Sürdürülebilir Girişimlerde İnsan Onuruna Yakışır İşler ve Düşük Karbon Ekonomisi, Ekonomik ve Sosyal Araştırmalar Merkezi Değerlendirme Notu: 2013-13. Retrieved from http://acikerisim. kirklareli.edu.tr: 8080/xmlui/bitstream/handle/ 20.500.11857/ 427/Ye\%C5\%9Fil\%20\%C4 \%B0 \%C5 \%9 Fler \% 20-\% 20KESAM. pdf? sequence $=1 \&$ isAllowed $=\mathrm{y}$.

Binici, A. (2013). Yenilenebilir Enerji Kaynakları Çok Geniş İstihdam Potansiyeline Sahip, Retrieved from http://www.alternatifenerji.com/yenilenebilir-enerji-kaynaklari-cok-genis-istihdam-potansiyeline-sahip/

Çatalkaya, C. (2009). Yeşil İşler ve Yeşil Yakalılar, Retrieved from http://www.cengizcatalkaya.com/yesilisler-ve-yesil-yakalilar/.

Çelik, M. (2016). Birgün Herkes Yeşil Yakalı Olacak, Retrieved from http://amfiweb.net/bir-gun-herkesyesil-yakali-olacak/. 
Yeşil, Y., Fidan, F. (2017). Çevresel istihdam bağlamında yeşil işlerde eğitim ve beceri kazandırma. International Journal of Social Sciences and Education Research, 3(2), 607-618.

Efendioğlu, Ü.D. (2013). Sürdürülebilir Kalkınma Yolunda Yeşil İşler, Gelişen İnsan Kaynakları Kariyer Gündemi Yeşil Ekonomi. Retrieved from http:/www.kariyer.org.tr/wp-content/uploads/2014/07/ KG_sayi03_kapakla_birlikte. pdf,.9-11.

ILO (2013). Sustainable Development, Decent Work and Green Jobs, International Labour Conference, 102nd session, Report V, Genova. http://www.ilo.org/wcmsp5/groups/public/---ed_norm/--- relconf/documents/meetingdocument/wcms_207370.pdf (01.02.2015)

Karakul, A. K. (2015 ). Türkiye'de Yeşil Ekonomiye İnsangücü Yetiştirme Politikaları: Ĕgitim İle İstihdam Bağını Yeniden Güçlendirme Fırsatı, 1.Uluslararası Avrasya Enerji Sorunları Sempozyumu, ss.389403. Retrieved from http://ikc.edu.tr/ckfinder/userfiles/files/SempozyumProgram.pdf.

Kişisel Gelişim Merkezi. (t.y.). Retrieved from http://www.kigem.com/insan-kaynaklarinda-yesil-yakalilar-donemi.html.

Özsoy, E.C.(2016). Yeşil İşler ve İstihdam Olanakları Üzerine Bir Tartışma, Aksaray Üniversitesi İktisadi ve İdari Bilimler Fakültesi Dergisi . 8(1), 51-59. Retrieved from http://iibfdergi.aksaray.edu.tr/index.php/asuiibfd/article/view/159.

Reyhan, S.A. \& Duygu, E. (2015). Çevre Politikalarında Yeni Bir Yaklaşım: Yeşil İşler ve Yeşil İstihdam, Memleket Siyaset Yönetim (MSY), 10(23), 21-39. Retrieved from http://www.msydergi.com/uploads/dergi/207.pdf

Sungur, Z. (2011). Türkiye’de Yeşil Yakalı Mesleklerin Gelişiminde Güncel Eğilimler, International Conference On Eurasian Economies, ss.154-159. Retrieved from http://www.avekon.org/papers/311.pdf.

Tükiye Ulusal Yenilenebilir Enerji Planı (2014), Retrieved from http://www.eie. gov.tr

Yeşil Ekonomide İnsana Yakışır İşler Türkiye Ulusal Çalıştayı (t.y.), Retrieved from http://www.bmdergi.org/tr.

http://www.oecd.org

http://www.ilo.org

\section{Extended abstract in English}

Kyoto Protocol; Investments in renewable energy production, awareness-raising efforts to protect the environment and biodiversity have brought new and different business fields to the agenda. Jobs that prioritize environmental sustainability, green jobs (professions) and those who are employed in these jobs are also called green catchers. It is known as a renewable energy consultant, renewable energy engineer, wind energy expert, green marketing consultant, green human resources director, environmental and energy law specialist, organic agriculture engineer, green (ecological) tourism and holiday specialist.

According to the ILO, the concept of green jobs can be achieved by transition businesses, enterprises and work markets to sustainable and low-carbon economy which provides decent work standards. The ILO says it is struggling with two fundamental problems for the twenty-first century. The first of these; the reality that harmful climate change which will seriously jeopardize the quality of life of present and future generations and the deterioration of natural resources; The second is poverty and unemployment (Başol,2013).

Especially in recent years by renewable energy investments and environment negotiations starting with the EU an increase have seen in green-fired professions in Turkey. Given the employment in the public sector in the environmental processes and those employed in the private sector in those sectors, it is assumed that there is an employment of 50,000 jobs. Especially wind energy, environmental engineers are becoming the main areas of this process. In the future, hydroelectric 
Yeşil, Y., Fidan, F. (2017). Training and gaining skills at green jobs in the context to environmental employment. International Journal of Social Sciences and Education Research, 3(2), 607-618.

power plants, wind power plants and geothermal projects are expected to create 100,000 more jobs. Sectors such as transportation, construction, energy and agriculture are already mentioned as areas where the potential for green business development is high (Sungur, 2011,p. 157). Green jobs do not only have a direct impact on the labor market in the form of high labor demand and job creation but also indirectly by creating jobs in other sectors due to the interrelationship of the sectors.

It is anticipated that the changes in the labor market and employment will take place in the framework of the green economy approach that sets the stage for the development of green jobs. In all countries which are independent from development level, these jobs are spread over a wide area according to differentiated skills, educational level and professional profiles. For this reason, green jobs are seen as jobs of the future and will be dynamic professions that involve creativity and lifelong education-exchange-development, which are made up of mixed disciplines or jobs. One of the key components of environmental employment that will become widespread in this context is that the training, knowledge, skills and abilities of the workforce need to be developed in a way that will provide a productive and sustainable environment and production mix, and that this combination can meet the multifaceted objectives as well as the technology needed. In this transformation process, training and skill development activities will have an important role.

In Turkey, at sectoral strategies development plans the importance of environmentally sensitive production are emphasized and practices are implemented. Depending on this development, green jobs are seen in many areas of the economy and activity. They have spread to many areas like energy, transportation, construction, agriculture and forestry particularly. Environmental protection is oriented towards key areas such as productivity increase and waste reduction. In this context, it is expected that transformation of existing professions will take place and green jobs will take a significant place in the labor market. It is seen that there is an important potential in the context of green jobs in Turkey. Especially "renewable energy" applications will be among the driving forces of green growth and will be a significant potential for green jobs.

Aim: Continuous training, development and adaptation skills need to be established for development and improvement at the job market and meeting the changing human resource demands. The green economy transition and climate change policies will affect the demand for new skills and skills in the labor force. It will not only create a new space called green business, but it will also lead to the structural transformation of existing businesses. A green economy causes some jobs in the market to undergo structural changes in employment and the labor market. This will require workers to be trained again or to be trained in a skilled workforce capable of doing new jobs. New technologies developed for a green economy can use these technologies, and moreover, they require labor to develop these technologies.

Researching green jobs are necessary for helping staff development at labor market and building training units which train human resources for these jobs. The aims of this study are examining the development of green jobs and their characteristics and differences from existing professions and evaluating training and gaining skills activities about green jobs. In this study, it appears that requires a different educational and training process of the characteristics of green jobs. The educational process will have the following characteristics;

- Dynamic, shows continuous change and development,

- It offers multiple skills and knowledge, 
Yeşil, Y., Fidan, F. (2017). Çevresel istihdam bağlamında yeşil işlerde eğitim ve beceri kazandırma. International Journal of Social Sciences and Education Research, 3(2), 607-618.

-It consists of an interactive process,

- It requires the cooperation of different institutions and bodies,

- It is interdisciplinary.

Green jobs require different training programs and processes according to other jobs. Green jobs are often "local" in nature and need appropriate training processes. The work to be employed in green jobs should be initiated with "awareness" activity. In the second stage, job-related information should be given and the third phase of practical training should be introduced. The cycle must be completed by fourth phase achieving the job and the developing the job in the fifth phase. Effective policies should be developed for green jobs and the labor market. Within this scope, training modules related to green areas and selected areas of activity should be determined and systems should be established within the framework of sustainability. 